\title{
La relecture de l'oeuvre par ses écrivains mêmes. Tombeaux et testaments - Tome I, sous la direction de Mireille Hilsum
}

\section{Gabriella Bosco}

\section{(2) OpenEdition \\ Journals}

\section{Edizione digitale}

URL: http://journals.openedition.org/studifrancesi/9078

DOI: 10.4000/studifrancesi.9078

ISSN: 2421-5856

\section{Editore}

Rosenberg \& Sellier

\section{Edizione cartacea}

Data di pubblicazione: 1 octobre 2008

Paginazione: 505-506

ISSN: 0039-2944

\section{Notizia bibliografica digitale}

Gabriella Bosco, "La relecture de l'oeuvre par ses écrivains mêmes. Tombeaux et testaments - Tome I, sous la direction de Mireille Hilsum», Studi Francesi [Online], 155 (LII | II) | 2008, online dal 30 novembre 2015, consultato il 11 janvier 2021. URL: http://journals.openedition.org/studifrancesi/9078; DOI: https://doi.org/10.4000/studifrancesi.9078

Questo documento è stato generato automaticamente il 11 janvier 2021.

\section{cc) (†) $\odot$}

Studi Francesi è distribuita con Licenza Creative Commons Attribuzione - Non commerciale - Non opere derivate 4.0 Internazionale. 


\title{
La relecture de l'oeuvre par ses écrivains mêmes. Tombeaux et testaments - Tome I, sous la direction de Mireille Hilsum
}

\author{
Gabriella Bosco
}

\section{NOTIZIA}

La relecture de l'oeuvre par ses écrivains mêmes. Tombeaux et testaments - Tome I, sous la direction de Mireille Hilsum, «Les Cahiers de Marge» n. 2, Paris, Éditions Kimé, 2007, pp. 240.

1 In copertina, una litografia di Tom Phillips ritrae Samuel Beckett di schiena che guarda il personaggio di Lucky. Il proposito del volume è quello di illustrare la pratica della rilettura delle proprie opere da parte degli autori, e la curatrice Mireille HILSUM, ritiene «l'auteur relecteur [...] un homme de dos dont les paroles sont a contrario lisibles au premier plan».

2 Frutto di due convegni entrambi organizzati dall'Université Jean Moulin-Lyon 3 (una giornata di studi svoltasi nel febbraio del 2005 e un Colloque international della primavera 2006), la miscellanea offre un ventaglio di riletture possibili che spaziano tra due posizioni agli antipodi: quella di Paul Valéry, che intende la pratica finalizzata a «refaire [...] son travail», implicitamente en mieux, e quella di Samuel Beckett che la sintetizza invece nell'ingiunzione inversa, «échouer encore». Tra il xviII e il xx secolo questo l'arco cronologico preso in considerazione - la rilettura di sé da parte degli autori risulta nascere quasi sempre da un desiderio di opporsi alla perdita e all'oblio: l'avvicinarsi della morte induce a volersi erigere un monumento funerario, e quindi a "rifare", o all'opposto a "disfare" ciò che si è fatto in precedenza. 
3 L'ampiezza dello spettro richiede una definizione del concetto preso in esame, «champ d'études relativement nouveau» sottolinea la curatrice, e il volume nel suo insieme la fornisce: relire corrisponde per lo più a élire.

Quattro le sezioni. La prima, «Vieillir, relire», propone un'attraversata di due secoli che associa Rousseau, Diderot e Nietzsche. Michael O'DEA affronta i primi due autori in contributi distinti («Un moins vieux ami»: Rousseau se relit, Rousseau se relira, pp. 27-35; e Le goût et la force: Diderot lecteur de son cuvre, pp. 37-49), mentre di Nietzsche si occupa Laurent MATTIUSSI (Nietzsche ou la relecture de soi comme destin, pp. 51-63).

5 Nella seconda sezione, «La scène et le livre», il percorso analizza le riletture che comportano dei passaggi di genere: dal teatro al romanzo o il suo opposto. Per il xVIII secolo, Christelle BAHIER-PORTE prende in considerazione il caso di Beaumarchais (Beaumarchais relecteur: du théâtre au «roman», pp. 67-80). Mentre per il xIX secolo si passa da Champfleury (Gilles BoNNET, Silences: Champfleury, pour une poétique de la relecture, pp. 81-94) a Zola (Jean-Marie SEILLAN, Relecture, reclassement générique et réception: Zola et «L'attaque du moulin», pp. 95-108).

6 Segue la sezione intitolata «Refaire/défaire», che oppone due casi ambigui, Crébillon e Gœthe (Régine JOMAND-BAUDRY, Crébillon relecteur d'«Ah quel conte!»: réinvention ou épuisement du genre?, pp. 111-124; e Martin RAETHER, "Le pêcheur»: Gothe relecteur refoulant, pp. 125-136) a due casi esemplari, Chateaubriand e Lamartine (Olivier CATEL, Relecture et réécriture dans «La vie de Rancé»: une esthétique de la mosaïque, pp. 137-153; e Aurélie LOISELEUR, Une mise en regard des «Méditations»: les Commentaires de Lamartine, pp. 155-169).

7 La quarta e ultima sezione, «Se relire ou non?», passa in rassegna alcune pratiche di rilettura particolarmente "spinose", da parte di autori non riconducibili a schemi di comportamento. Aude DÉRUELle studia il caso di Balzac che, diventato legittimista, rilegge due volte Le Dernier Chouan (1829), nel 1834 e nel 1844, senza tuttavia imporre alle due versioni riscritte un sovrasenso ideologico (Relecture et illisibilité: "Les Chouans" de Balzac, pp. 173-186). Françoise GENEVRAY cerca di stabilire in quali casi si rilegge George Sand, autrice per la quale non ci sarebbe creazione romanzesca se non attraverso il filtro dell'oblio (Lorsque George Sans se relit, pp. 187-199). E Stéphanie DORDCROUSLÉ si cimenta con Flaubert, che rilegge l'Education sentimentale da un lato ricreando «sous le signe du hasard et de la discontinuité», d'altro lato senza preoccuparsi della grande quantità di coquilles introdotte dall'editore (Flaubert relecteur de lui-même: le cas épineux de l"Education sentmentale", pp. 201-214). Il xx secolo è affrontato nel contributo conclusivo: Florence GODEAU sigilla il volume affrontando il caso estremo, quello di autori - Proust e Musil - per i quali la rilettura è pratica inscindibile dalla genesi del testo (Relecture et inachèvement: Marcel Proust, Robert Musil, pp. 215-226). 